\title{
C. Wright Mills' The Sociological Imagination and the Construction of Talcott Parsons as a Conservative Grand Theorist
}

\author{
Helmut Staubmann ${ }^{1}$
}

Accepted: 25 September 2020 / Published online: 10 October 2020

(C) The Author(s) 2020

\begin{abstract}
C. Wright Mills was one of the most important critics of Talcott Parsons who succeeded in establishing the image of Parsons as a conservative "grand theorist" out of touch with the real world and its real problems, as passed on in sociological textbooks. In this essay, it is argued that Mills' "translation of Parsons into English" is a one-sided interpretation based on his own theoretical premises, which he called the sociological imagination. The way Mills conceptualized sociological imagination leans towards an ideological world-view with political ambitions but lacks the necessary theoretical differentiation for an adequate evaluation of Parsons' general theory of action and the conceptualization of the social system in particular. Given Mills' premises, it appeared to him as if Parsons could not deal with social conflict, social change, domination and power relationships, which laid the foundations of a narrative quite distinct from the "real" Parsons. The conceptual deficiencies of Mills' sociological imagination lead into theoretical antinomies and the practical inability to resolve political issues outside of forceful intervention as suggested in the theoretical tradition of Thomas Hobbes. Independent of a political positioning, Parsons' sophistications in his understanding of power as one of several generalized symbolic media of interaction beyond the Hobbesian utilitarian model are necessary to come to terms with the increased complexity of modern society, both in theoretical and in political terms.
\end{abstract}

Keywords Conflict $\cdot$ History of sociology $\cdot$ Philosophy of the social sciences $\cdot$ Power . Social theory

Helmut Staubmann

Helmut.Staubmann@uibk.ac.at

1 Department of Sociology, University of Innsbruck, Universitätsstr. 15, 6020 Innsbruck, Austria 


\section{Introduction}

"... as from a prophet who comes in from a desert" - such should be the effect of the publication of a manuscript entitled The Sociological Imagination (1959) written in Europe $^{1}$ in 1957 , as the author C. Wright Mills noted in a letter to the historian William Miller on March 14, 1957 (s. K. Mills 2000: 230). The author's wish would become true. This publication eventually turned into one of the most powerful books in the history of sociology. In 1997, the International Sociological Association conducted an opinion survey on the most influential books in sociology published in the twentieth century. Mills' The Sociological Imagination reached the second rank after Max Weber's Economy and Society (2019 [1922]). Talcott Parsons got about half as many votes as Mills for his The Structure of Social Action (1937) and ended up on rank nine.

Yet, the lasting effect $\mathrm{C}$. Wright Mills has had up to our times might not so much be based on his original writings which are less received by the younger generation of sociologists than through setting the directions of the discourse at the time by coining concepts and labels that were broadly accepted and included in sociology textbooks. We all know that a considerable segment of textbooks has a life of its own, often detached from the real world they pretend to stand for (s. Mahlert 2020). Still, textbooks are a sort of RNA of scholarly fields in that they reproduce and spread the information from generation to generation.

The most famous of the respective labels coined by Mills is "grand theory" and its attribution to Talcott Parsons as its foremost representative. With the label of grand theory comes a whole syndrome of unfavorable designations like "fetishism of the concept" (Mills 1959: 35), the inability to deal with social conflicts and societal change, with domination and power relationships etc. which all, in political terms, translate into an image of Talcott Parsons as a conservative and apologist of the deficiencies of Western modernity and capitalist societies. ${ }^{2}$

\section{Talcott Parsons and his Strawman Double}

There is a peculiarity in the assessment of Talcott Parsons' legacy and the political role he played, which, to my knowledge, is unique in the history of social thought. The common situation is that creative thinkers come up with new ideas that eventually crystallize in schools of thought, gaining permanence if a group of followers is able to position themselves in academic institutions. This kind of tribal organization of sociology, as Niklas Luhmann once called it with his peculiar irony, is the basis of ongoing controversies over more or less antagonistic positions like methodological individualism versus methodological collectivism, or the prevalence of cultural versus "material"

\footnotetext{
${ }^{1}$ In March of 2018, Kathryn Mills, daughter of C. W. Mills, gave a lecture at the University of Innsbruck in which she talked about details of her and her family's time in Innsbruck, Austria. According to her, large parts of the manuscript of The Sociological Imagination were written here during a difficult familial situation (s. K. Mills 2018; Staubmann and Treviño 2018). Having Kate Mills as a guest in my department was a great honor and touching experience. Since then, we have maintained a cordial exchange and friendship.

2 Talcott Parsons, in "The Distribution of Power in American Society" (first published in 1957), had written a profound critique of Mills' The Power Elite well before Mills critiqued his work in The Sociological Imagination.
} 
factors in social life. In the case of Parsons, however, it is often not so much a matter of conflicting standpoints. The problem is more confusing to begin with, since a quite large circle of experts unanimously contests the accuracy of the critics' understanding of what Parsons's theory, and consequently its political implications, are about. In this regard, Harold J. Bershady wrote: "Much of Parsons' work has been contaminated with false and essentially unscholarly accusations. ... It is to be hoped that once a clearer and more truthful picture of him emerges, the theory of social action will gain greater moral approval..." (2014: xix).

A prime example of a misleading label concerns structural-functionalism and the unshakable conviction that Talcott Parsons was its inventor and foremost representative. The historical fact is that there was only a short period in the early 1950s where Parsons situated himself in the broader current of this methodological position developed and held by a group of anthropologists, ethnologists and sociologists. He later argued against the linking of structure and function and explicitly did not want to be subsumed under the label of structural-functionalism. However, it was all in vain. Neither reminders on the historical facts nor Parsons' own protest sufficed to change the critics' belief.

Another claim against all evidence, with resulting attacks spanning over decades, is that Parsons did not and could not deal with societal change after he had written several books and a considerable number of essays on the dynamics of societies and after he had analyzed major evolutionary and revolutionary changes in a more elaborate and refined way than those who could only make out harmony, integration and equilibrium in Parsons' writings. ${ }^{3}$ The reason, as we will argue with the example of C.W. Mills, lies in a specific understanding of conflict, domination and social change inherited from materialistic positions of nineteenth century thought.

These misrepresentations of Parsons' standpoints find their continuation in the widespread opinion of the incompatibility of theory developments carried out by some of Parsons' students. Harold Garfinkel or Clifford Geertz, for example, were favorably received at their time and up to contemporary sociology. They are presented as Parsons' irreconcilable opponents which is against the facts and against explicit statements, by both Parsons and his famed students. Recently, Anne Rawls published an illuminating manuscript written by Garfinkel in the late 1950ies and early 1960s which Garfinkel had used in his courses. The book entitled Parsons Primer (2019) displays the deep understanding and appreciation Garfinkel had for his teacher. He makes clear that he had learned the fundamental meaning of interaction for culture and social systems in collaborations with Talcott Parsons, which led him to develop what became known as ethnomethodology (s. Rawls and Turowetz 2019). Parsons' critics effectively could establish the belief of an utter opposition between Garfinkel and Parsons. Anne Rawls and her collaborator Jason Turowetz sum it up: "We argue that these criticisms do not target Parsons' actual position, but a misinterpretation of it

\footnotetext{
${ }^{3}$ A good example is Parsons' concern with the political situation in Germany, particularly the rise of National Socialism as documented by the essays "Democracy and Social Structure in Pre-Nazi Germany" and "Some Sociological Aspects of Fascist Movements" included in Essays in Sociological Theory (1949, first edition) along with other essays dealing with social change and conflict like "The Problem of Controlled Institutional Change", "Certain Primary Sources and Patterns of Aggression in the Social Structure of the Western World", or "Social Classes and Class Conflict in the Light of Recent Sociological Theory". Furthermore, Parsons served as scientific advisor for the Council of Democracy, voicing concern about changes in Germany as well as in Japan towards post-war democracy.
} 
popularized in the 1940's and 1950's and subsequently criticized in the 1960's and 1970's." (Turowetz and Rawls forthcoming) They conclude: “... the version of Parsons these approaches oppose is a strawman."

This means that there is Talcott Parsons and then there is, let's say, a persistent narrative about Talcott Parsons which is only remotely related to the "original". C. Wright Mills was undoubtedly one of the most important figures in the establishment of such a narrative. It is this decisive role in creating a distorted image of Talcott Parsons and what consequently turned into a kind of "ritualistic Parsons slaughter," as Roland Robertson expressed it aptly, that makes it worthwhile looking into how Mills perceived and judged Parsons' work, how he drew his conclusions and, conclusively, why his writings resonated so well with the intellectual climate of the time and even with contemporary sociology. ${ }^{4}$

Constructivist perspectives suggest that observations are dependent on the observational schemes used; the frames of reference, to put it in Parsonian terms. This view will serve us as a starting point to explain the specific approach Mills led to arrive at his judgments on Talcott Parsons by looking into the presuppositions of his own theory. We will at first reconstruct Mills' argument and subsequently compare the relevant underlying concepts with the ones of Talcott Parsons.

\section{Sociological Imagination: Promises and Disappointments}

"The Promise" is the title of the first chapter in The Sociological Imagination. What is the promise about, what role could sociology play and to whom is it addressed? The starting point is the assertion that society is in a terrible state, haunted by unruly forces, by anarchy, and by alienation, to use Mills' expressions. The problem, according to Mills, is not confined to American society, since history turned into world history in the twentieth century. And Mills draws a dismal picture of ongoing developments: colonialism was replaced by less visible forms of imperialism, the majority of people find themselves excluded from democratic processes, and democracy as such was transformed into mere formalistic procedures. "Everywhere in the overdeveloped world, the means of authority and violence become total in scope and bureaucratic in form." (1959: 4) And things might even turn worse: The powers are "concentrating ... [their] ... most coordinated and massive efforts upon the preparation of World War Three" (4) a danger on which Mills had published a book the year before (s. Mills 1958).

Individuals are the victims of such societal circumstances without being able to grasp the structural problems in which they are trapped. They experience individual fates, private troubles, but cannot perceive the "real" reasons behind them, which are the "public issues", i.e. the institutions and larger structures of society that constrain the lives of individuals.

According to Mills, the solution is a new "quality of mind" called sociological imagination. It

\footnotetext{
${ }^{4}$ There are more sophisticated critiques of Parsons'work, that would be worthwhile responding to, but it was precisely Mills' bold style that resonated well and thus contributed more effectively to the distortion of Parsons' image.
} 
"... enables its possessor to understand the larger historical scene in terms of its meaning for the inner life and the external career of a variety of individuals. It enables him to take into account how individuals, in the welter of their daily experience, often become falsely conscious of their social position." ... "The sociological imagination enables us to grasp history and biography and the relations between the two within society. That is its task and its promise." (Mills 1959: 5-6)

Let's look into one of the examples Mills provided: the case of a failed marriage. Through the lens of a married person, most cases of divorce are undoubtedly troubling personal experiences. Empirical data accumulate these experiences to increasing divorce rates which have structural causes like concomitantly rising unemployment rates. So, a divorce appears as an individual problem but is "in reality" a societal problem and thus can only be resolved by changing the structures of society. "Tracing such linkages" ... "is to possess the sociological imagination" (Mills 1959: 11). This example gives a foretaste of Mills' sociological reductionism, i.e. his attribution of "real causal factors" to society; a principle, which is a crucial starting point of his critique of Parsons' theory of social systems.

Mills' ambitions thereby are in no way moderate. The claim is that sociological imagination is the intellectual common denominator of contemporary cultural life (s. Mills 1959: 14), a world-view comparable to Newtonian physics and Darwinian evolution theory, which also represented the basic intellectual orientation in their time. According to Mills, it is the basic intention of his book to lead the social sciences into fulfilling this cultural task.

The social scientists, however, to the dismay of Mills, have followed quite different imaginations and taken different paths. In the eyes of Mills, some simply pursue the development of a "set of bureaucratic techniques" (Mills 1959: 20). In doing so, they distort the "real" knowledge about society, which he calls abstracted empiricism, while "some - being addicts of the high formalism of theory - associate and disassociate concepts in what seems to others a curious manner" (Mills 1959: 20) - all this in association with abstract and static views. Although the first names Mills mentions here are interestingly Georg Simmel and Leopold von Wiese, we have finally arrived at the section entitled grand theory, a chapter dedicated to a critique of Talcott Parsons.

\section{"Grand Theory" and its Discontent}

The vocabulary Mills uses to characterize Parsons' work is not very flattering: arid formalism, void phrase mongering, confused verbiage, endless elaboration of distinctions, drunk on syntax - blind to semantics, splitting of concepts and endless rearrangement; although we could go on we want to stop here. In a relatively sober formulation, "grand theory" is defined as "the associating and dissociating of concepts “(1959: 26).

Mills elaborates his objections to Parsons by scrutinizing mostly The Social System (1951). The subtitle of the book, which Mills does not mention anywhere, is: The Major Exposition of the Author's Conceptual Scheme for the Analysis of the Dynamics of the Social System. The publication includes two chapters exclusively dedicated to the dynamic processes and processes of change in social systems. To be able to judge 
Mills' verdict of the book in reverse, we need to keep the two claims expressed in the book title in mind: firstly, the elaboration of a conceptual scheme (not the analysis of an empirical, historically given social system, an analysis of any societal state etc.) and secondly, a focus on the dynamics of social systems.

Before going into the specific objections of Mills against The Social System, we need to clarify the concept and role of theory in social sciences as such. Theory is one of the two pillars sociological inquiry rests on, the other one being methodology. There are two basic tasks or, I hesitate to say, "functions" of theory. The most important one is the construction of the basic concepts that give the discipline its identity. Let's call it the a-priori function. Here, the founders of sociology had to overcome the "raw" and undifferentiated kind of everyday life-world understanding of social phenomena and thus took up the burdensome endeavor of what sometimes appears to some young sociology students as an "endless" arrangement of concepts. Max Weber's essay on "Basic Sociological Concepts", included in Economy and Society (2019 [1922]), is a conspicuous example thereof. The classical founders had to do so because commonsense life-world concepts with their lack of sophistication soon lead to aporias, as all undifferentiated concepts eventually result in confusion. Thus, there are good reasons for splitting concepts and (re-)arranging them into a coherent system. Talcott Parsons dedicated his first masterpiece, The Structure of Social Action (1937), to the task of refining the theoretical traditions, precisely to overcome "arid" controversies over idealism and materialism and, closely related to the issue, reductionisms of all sorts. The increasing complexity of the theoretical system - and Parsons' further refinements led to an undoubtedly high degree of sophistication - is demanding, but the alternative is the regression into a pre-disciplinary social science guided by everyday life-world concepts and driven by mostly political agenda. Expressed with reference to Mills' words: sometimes it pays to concentrate on syntax, leaving semantics aside. The development of the discipline of semiotics illustrates this point.

However, Mills is totally right in his assertion that "semantics" is indispensable after all. This leads us to the second meaning of sociological theory: its a-posteriori function. Based on well-defined concepts, as Emile Durkheim had demanded as the first and foremost rule of sociological inquiry (1982 [1895]), we now can use them to empirically explore the social and cultural world. This eventually leads to "substantial" or "empirical" theories, like Weber's theory of modernity or Durkheim's theory of suicide, to name just two of the most prominent examples. These "concrete" applied theories are, as Parsons repeatedly stated, the ultimate test and ultimate goal of any theoretical scheme.

The dividing line between Mills and Parsons in purely theoretical terms is the sophistication of the theoretical frame. Generally speaking, we can say that the complexity of a theory correlates with the possibility of differentiated knowledge, or, using Mill's terminology: the more advanced the syntax of a language, the more options there are for semantics and consequently for thinking and for communicating. Insufficient conceptual differentiation leads to blindness in empirical terms, as we have known ever since Immanuel Kant's famous formulation. And Mills provides ample evidence thereof in what he subsequently calls a translation of Parsons into English.

Indeed, many feel that Parsons' formulations could be improved stylistically; even Parsons himself. However, Mills' translation did not make it easier to understand what Parsons had to say. Instead, it was a translation into his own thinking, the limitations of 
which led on the one hand to what Parsonians perceive as a distortion, the kind of simplified strawman edition Rawls and Turowetz described. Marx might have used the word phantasmagoria here. On the other hand, Mills' translation brought forth the sharp contrast between his style of thought and Parsons' theoretical system. Or, put differently, Mills used Parsons' general theory of action as a sort of projection screen, eventually making his own theoretical shortcomings visible.

Mills begins his argumentation with an extensive sample quote, his aim being that the readers would self-evidently perceive this as void phrase mongering. This quotation technique itself is somewhat questionable, as any small portion of text taken out of the context of a complex argument poses difficulties to readers. Besides such stylistic issues, however, the difference lies in two concepts/conceptual differentiations completely alien to Mills' thinking: one is the double contingency of interaction, and the other the clear distinction and assumption of the structural independence of a personality, a social system and a cultural system. This conceptual differentiation is indispensable for the understanding of the stability or instability of social systems.

\section{The Hobbesian Problem of Chaos}

The famous expression "the Hobbesian problem of order" is rather misleading. What Hobbes tried to resolve in practical and in theoretical terms was not order, it was chaos. The question arose in the context of a highly disordered cultural and political situation in seventeenth century England. Based on what we now call the utilitarian model, which assumes that humans "naturally" inherit egoism, causing "war of all against all" - as Hobbes had interpreted his observations at the time - he saw the solution in a sovereign, an "absolute" ruler who is able to control the situation in a way that everyone is better off when conforming with the government, the means of which could ultimately only be force. Such a view, however, covers only a very limited range of empirical cases. Luckily, humans are not hedonistic creatures triggered by situational pleasure or pain causing factors. As social beings, they have not only egoistic impulses but also altruistic ones; they orient themselves towards others and their expectations, as well as committing themselves to social norms and cultural values, so that Parsons, based on a more realistic albeit complex model, could write: "The problem of order ... thus focuses on the integration of the motivation of actors with the normative cultural standard which integrate the action system..." (quoted in Mills 1959). While Mills, quite in line with Hobbes, perceived a kind of primordial opposition between social structure and individual agency, Parsons clearly identified the balancing mechanisms and pointed to common culture, norms, value orientations and shared symbols, all of which link individual motivations and social structure. This is by far not trivial. At least Mills did not seem to understand it. It is important to stress that Parsons thereby identified the preconditions of social order, while explaining social disorder at the same time and to the same extent.

When Mills narrows his objection down to the assertion that "an institution is a set of roles graded in authority" (1959: 30), implying that some assert their power over others, he fully stands on the grounds of Hobbes' utilitarian model. Despite the fact that he is indeed right to draw attention to armies, factories or families - to take up Mills' own examples - where some exert force over others in the sense of the Hobbesian model, we would not have families, factories or armies if this were essentially the 
"normal" case. On the contrary, as Parsons would formulate later, deflationary forms of authority, the regression to means of force, lead to unstable situations. The minimum conceptual differentiation necessary to see the problem is the structural independence of individuals with their need dispositions, of culture and of social institutional structures. This is the basis of a theory of the dynamics of social systems that is anything but static, as Mills erroneously concluded. Mills should have taken the Parsons-quotes he himself had selected for his chapter to heart:

"That the stability of any social system ... is dependent on a degree of such integration may be said to be the fundamental dynamic theorem of sociology. It is the major point of reference for all analysis which may claim to be a dynamic analysis of social process." (Parsons in Mills 1959: 30-31)

Since Mills interpreted this quote from the perspective of his societal force versus individual fate distinction, it appeared to him as if Parsons demanded conformity to societal rules from individuals, in order to give the social system unchangeable stability. The entire alleged "over-socialized man" model (Wrong 1961) in Parsons' theory is based on such a misreading. However, it was not meant this way. An unprejudiced reading of The Social System would have made clear that the relationship between society and individuals is a co-evolutionary one in which mutual adaptation, for which Parsons used the word integration, is a major factor in the dynamics of action systems. So Mills' assertion that "no explicit meaning is lost" in what he called his "straightforward translation" (p. 31) of parts of The Social System into English has departed far from the text's actual stated intention. And so is his conclusion that Parsons is unable to explain disequilibrium and social change in empirical terms.

\section{The Self-Reference Paradox of Mills' Sociological Imagination}

From a political perspective, a sociological imagination is extremely limited if it only attributes the causes of "individual troubles" to the structure of society. Who would be able to make the desired changes, the reforms or perhaps even revolutions? This exposes a self-reference paradox that is well known from all materialistic theories oscillating between the idea that humans are the product and thus mere victims of circumstances, while at the same time demanding political action from exactly these "products". In the end, such a model requires a deus ex machina, or, in the words of Mills, "a prophet that comes in from a desert".

In line with Mills, intellectuals at the time tried to outdo each other in attributing the discontents of life - of alienation - to some exteriorly conceptualized society or some concrete or generalized "other". Jean-Paul Sartre, to whom Mills had close contact, 5 epitomized it with the famous dictum: "Hell is other people". An upright sociological imaginative mind immediately sees the self-reference issue associated with this proposition because it only can be true if an individual, let's call her/him ego, is set absolute.

\footnotetext{
${ }^{5}$ In particular, they shared a common interest in the Cuban revolution. In the summer of 1961 Mills met with Jean-Paul Sartre and Simone de Beauvoir in Paris (s. Treviño 2017: ix and K. Mills 333f). A review of Beauvoir's Second Sex by Mills appeared posthumously under the title "Women: The Darling Little Slaves". (s. K. Mills 333)
} 
From an individual perspective, this might appear as fully accurate but for a sociological observer, it is clear that ego and alter perspectives are interchangeable. Therefore, ego must conclusively be hell for alter in reverse, and the ultimate conclusion then is that ego is hell for her/himself, which at times comes closer to the truth anyway. However, the fallacy lies in the theoretical model on which the contention is based with its lack of differentiation. For it might also be true that "heaven is other people", ultimately making it an empirical question, whether the one or the other is the case or some state in between which is, in the long run, the normality. This is just another example that the sheer "endless elaboration of distinctions" (Mills 33) bears fruits at times, as without the distinctions one is stuck in a one-sided and often improbable dismal picture of reality.

The self-reference issue in Mills' case gets even worse when we consider what happens if this prophet finds followers and gains power - power and authority the way it was defined beforehand. Hobbes' conclusion was clear: the solution is an absolute sovereign who rules the people with the ever-present force as the base of her/his power. A look into history teaches us that this actually sometimes did happen with disastrous consequences. Given the theoretical premises of Mills' theory, we could never escape the ordeal of "unruly forces" and would be trapped in a choice between being ruled by capitalist power elites or a left-wing power regime. However, there is good reason to believe that the premises are wrong and that pursuing theoretical and practical alternatives is worthwhile.

\section{Double Contingency}

Closely associated with the issue of a blind spot for self-reference in mechanistic thinking is the difference in Mills' and Parsons' conception of the most basic sociological concepts, those of communication and interaction. A mechanistic understanding, as is common in everyday life, attributes the causality to one side of the individuals involved in these processes. In communication, the "sender" of information usually bears the burden of causality. As for the case of interaction, the one who "wants" or "demands" something is thus deemed "dominating" or "superordinate" over the one who gives something or provides a service. The result is a splitting of the mutuality of communication and interaction into one-way units which in summation is taken as the whole communication or interaction process. Such an understanding misses the systemic quality of social processes for which Parsons coined the term double contingency, a functional source for an emerging common culture. It is implied that both sides are "to the same extent" causally involved. Ordered and "successful" communication and interaction processes are - as the concept has it - contingent on both or all sides involved and thus could not occur otherwise. "To the same extent" only means that they are both indispensable conditions for the interaction to occur and thus a quantification of the extent of the causality makes no sense.

Georg Simmel's concept of social interaction, literally translated as "social mutuality of cause and effect" (soziale Wechselwirkung) precisely captures this point. That is why he came to the same conclusions; e.g. in his essay on domination and subordination [1908] he argues that a mechanistic understanding erroneously attributes the causality in such relationship types to the apparently dominating part. The expression "apparently dominating" refers to the fact that it frequently cannot be decided if someone is in 
a dominating or sub-ordinate position. For example, journalists exert influence on the audience and at the same time try to write what the audience wants to hear to be successful. In the more abstract formulation of Talcott Parsons it reads: "What are expectations to ego are sanctions to alter and vice versa" (1951: 40). Such an insight into the mutuality in interaction is completely alien to Mills and this might explain why he aligns Simmel with Parsons in the grand theory chapter. His assessments of the conditions of society display a strict one-way causality, particularly of socioeconomic and political processes.

Mills actually provides a quote that includes the term double contingency (1959: 25) but obviously did not see its relevance and thus paid no further attention to it in his "translation" endeavors. Once more, the reason is obviously a blind spot based on Mills' design of a sociological imagination.

\section{Power}

"Interaction" based on pure force is a limiting case. Strictly speaking, it is not "inter"action at all but action exerted by someone on some other, only contingent on the person having the means of force. Unfortunately, this occurs from time to time but to generalize such cases as being the essential form of interaction in modern society is far from reality. This also applies to interaction in connection with political goals. Here we have the most obvious opposition of Mills against Parsons, which crystallizes around the concept of power.

A first difference lies in Mills' conceptualization of power as a means for some to pursue self-interested goals over others, while Parsons conceptualized power as a medium for the attainment of collective goals, a functional problem that needs to be resolved in all social systems. The basic issue is consensus, not on the specific decision but on the legitimacy of the decision, for which the circulation of power as a symbolic medium is a decisive prerequisite (s. Lidz and Staubmann 2020). It is clear from the onset that these definitions of power are incompatible. For Mills it is a matter of a onesided exertion of the will of some on others, for Parsons it is a phenomenon anchored in the mutuality of interaction.

A consequence of the mutuality is that it creates an overall surplus so that the gain of one party does not equal another's loss. The motive to engage in an economic exchange is the expectation on both sides to have more afterwards and the same is valid for other types of interaction, e.g. in collective decision making. In all such cases, interaction does not equal a zero-sum game. Parsons explicitly referred to Mills in his essay on power, ${ }^{6}$ to point out the difference:

"The dominant tendency in the literature, for example in ... C. Wright Mills, is to maintain explicitly or implicitly that power is a zero-sum phenomenon, which is to say that there is a fixed 'quantity' of power in any relational system and hence any gain of power on the part of A must by definition occur by diminishing the

\footnotetext{
$\overline{6}$ Talcott Parsons' famous essay "On the Concept of Political Power" appeared at first in 1963, a year after C. W. Mills had died and Parsons' review of The Power Elite appeared the same year as The Sociological Imagination. Therefore, the quoted references of Mills to Parsons and vice versa cannot be interpreted as an exchange between the two. The section on power in this essay is intended as a reconstruction of their opposing views and their critique of each other.
} 
power on the part of other units, B, C, D,... There are, of course, restricted contexts in which this condition holds, but I shall argue that it does not hold for total systems of a sufficient level of complexity." (1969: 353)

Such a conceptualization of power as a generalized symbolic medium of communication and interchange does not mean to neglect many of the issues Mills refers to. There indeed is evidence of forceful domination occurring in complex societies, much of which is actually deemed deviant or criminal behavior. However, these problems would be unresolvable if interaction were essentially one-sided and a zero-sum process. Marx was theoretically consistent in that he suggested reversing the "unruly force" of the bourgeoisie into a dictatorship of the proletariat, but since the times When Marx Mattered (Bershady 2016), history suggests to better pursue other solutions. As Parsons wrote in a personal history, he held the view that it could no longer be a matter of the substitution of the capitalist pursuit of self-interest by a "rigidly centralized control by government in the public interest". The overcoming of "the rigid capitalistic - socialistic dichotomy" (Parsons 1977: 57) is possible on the basis of a broadening of a sociological imagination by taking other factors into account, such as voluntary associations, normative structures linked to cultural values and constitutive-religious beliefs.

Parsons especially emphasized what Durkheim had called solidarity, its "affective grounding ... in the motivational attachment of individuals to roles, to the collectivities in which they participate, and to their fellow members" (1977: 57). In contrast, for Marx and his followers, solidarity was clearly a utilitarian concept where people unite based on the same self-interest, as they share similar social conditions and status, but only if they turn from a class in itself to a class for itself, which again requires some external political agency.

Another characteristic associated with the zero-sum proposition for exchange in Mills' sociological imagination is the equation of power "with all forms of capacity to gain ends" (Parsons 1969: 297). If all give and take were a zero-sum phenomenon, then indeed it would not matter if a "transaction" were based on force or love or religious beliefs. In each of these cases it would mean the exploitation and subjugation of one person, or group of persons, by some other. The ability to acknowledge altruistic affective attachments, which in larger social systems lead to solidarity in Durkheim's sense, is connected with differentiations for the description of forms of exchange. Parsons' media theory discerns specific media for what he called subsystems of the social system and of the general action system. This conceptual refinement is indispensable, to see the difference in whether the goals in interaction are reached by threatening the other person, by agreeing consensually on common goals, by offering money, or by appealing to their solidarity, responsibility and shared values. Mills, as his fellows in "critical theory", conclusively "deconstructs" all these different means as "in reality" equaling "in the last instance" violent means of power. This becomes particularly clear in the passages Mills wrote on "the symbol sphere".

To sum up, the differences of Parsons' concept of power in contrast to Mills' can be broken down into three key points: 1) power is a discrete mechanism different from money and influence and embedded in different institutions; 2) power has the potential for transcending zero-sum relations; and 3) power is a facility or means of collective goal attainment, not just a way of securing personal interests. 


\section{“Symbol Spheres"7: Culture as Mere Legitimation of Domination?}

The utilitarian power concept Mills advocates is continued in his judgments on culture, "the symbolic sphere", as he calls it, with its "alleged autonomy" (1959: 36). Consequently, for Mills, values and normative structures are the "master symbols of legitimation" of domination. Culture is merely used by "those in authority" to justify their rule.

"Such symbols ... do not form some autonomous realm within a society; their social relevance lies in their use to justify or to oppose the arrangement of power and the positions within this arrangement of the powerful..." (1959: 37)

For Parsons, in contrast, orientation towards culture as such plays an important role for the understanding of the structures of social systems. He understood it as a differentiated subsystem with moral-evaluative culture as having a special importance for social normative order. Structural units, such as roles and institutions, integrate interactional expectations with cultural patterns. This is the case in such diverse areas as the institution of private property or the institution of marriage. The result is the emergence of social norms for concomitant interactions. These cultural and normative references suggest a dynamic in social systems independent of coercion, since commitments to culture and sensitivity towards the attitudes of others are decisive principles when engaging in interaction. This is the basis of Parsons' assertion that there is a cultural component inherent in every interaction, implying that there are powers in human life, which are entirely distinct from any pursuit of egoistic interests and striving for domination.

To contest this insight, Mills attacks the idea of the cultural quality of institutions. For him, social structures defined in this way obscure their "real" meaning: "The result, I think, is to transform, by definition, all institutional structures into .... what has been called 'the symbol sphere'. "(1959: 36) And this symbol sphere serves no other purpose than the justification of authority and power, e.g. in the cases of "widely believed-in moral symbols, sacred emblems ... god or gods ... "vote of the majority" etc. Capitalists, according to Mills, use such ideas to disguise their self-interest - since "the old self-interest motives and reasons may lead to guilt or at least to uneasiness among capitalists" (36-37). Conclusively, Parsons' "value-orientations and normative structure has mainly to do with master symbols of legitimation."

The provided quotes include the curiosity that a "vote of the majority" is deemed as mere means of the rule of authorities. Even if from time to time one hates the outcome of such majority votes, the question is what an alternative would look like. A comprehensive sociological imagination only brings up scary scenarios.

Besides such open democracy deficit issues, Mills' view on the role of culture in society comes down to a crude form of functionalism. Here, once again, we come

\footnotetext{
7 "Symbol Spheres" is the title of a chapter in Character and Social Structure (1953), a book Mills authored together with Hans Gerth. There they present a comprehensive social theory based on a synthesis focusing on Marx, Weber, and American pragmatism. Their specific understanding of power, of authority and of "the symbol sphere" as a means to legitimize domination became the conceptual tools Mills used in his Parsonscritique in The Sociological Imagination.
} 
across a paradox still living on in the context of what now is called cultural sociology. ${ }^{8}$ In line with Mills, a broad current of "critical" thought criticizes functionalism in abstract terms and at the same time adheres to a reductionist functionalist interpretation of culture as "in the last instance" serving economic and political interests. Culture is frequently directly equaled with economic capital and power, and a plethora of cultural studies outbid each other in "deconstructing" cultural preferences and activities, as motivated by the pursuit of economic self-interests.

The result is a blind spot for one of the most powerful phenomena in individual and in social life, namely the contents and forms of culture as such. Culture can indeed be used for all sorts of purposes, no doubt also for the ones Mills pays attention to, which I have suggested be called the "heteronomous function" of culture (Staubmann 2005). However, much more important, both for individuals and for society, is the role culture plays as such, its "autonomous function". A specification of the latter for social systems theory is the idea of the fiduciary function of a subsystem, the roles and institutions responsible for the preservation and furtherance of culture. Parsons' and Platt's study on the American university system (1973) shows how rational culture interpenetrates with all parts of what Parsons calls the general actions system, the enormous meaning of rational knowledge and values for social and individual life and even for an overall characterization of modern society.

Mills' repudiation of the autonomous role of culture leads him to deny that social structures are inherently also cultural phenomena. He repudiates Parsons' social structures concept but does not explicitly define what he calls "the structural features of human society" anywhere. We can only guess when he refers to a "set of institutions" that "controls the total society and superimposes its values by violence and the threat of violence" (1959: 39). This reminds one of a number of totalitarian communist states, which Mills most likely did not have in mind. However, even in these cases, sheer violence would not be sufficient to explain their temporal stability.

\section{Conflict and Social Change}

Given Parsons' extensive writings on social and cultural change, the persistent narrative of his lack and incapability to deal with the issue is stunning. Here again it is a matter of undifferentiated conceptions that account for a distorted perception of his work, one of which is the a-priori linking of social change with conflict. In Mills' words it reads: "The magical elimination of conflict, and the wondrous achievement of harmony, ... remove from this 'systematic' and 'general' theory the possibility of dealing with social change ..." (1957: 42). Such a "conflict perspective" - as it is called - is limited by the fact that conflict and change are "independent variables".

With the help of Parsons' theory technique of crosscutting such variables, we get a fourfold table in which, let's say, the rows represent the presence and absence of conflict and the columns show the presence and absence of social change. In assessing the four fields of our table with empirical/historical data, we realize that the presence of conflict in no way necessarily induces social change. On the contrary, a certain level of conflicts is a prerequisite of a stable social system. Niklas Luhmann, one of Parsons' most accomplished students, even saw conflicts as a sort of immune system that

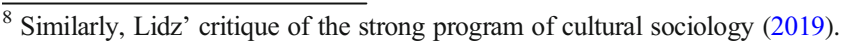


prevents social systems from falling apart, thus contributing to their durability. Expressed in Parsonian terms, conflicts are, to a degree, indispensable for the homeostasis of social systems. In proceeding to the next field of our fourfold scheme, we sometimes observe that conflict indeed may lead to social change, which Parsons acknowledged in his writings accordingly.

Finally, we have the important cases where social change occurs without being induced by any conflict at all. Historically, this is especially the case with cultural innovations that influence social structures and processes. To name one example, there is vast literature on the far-reaching impact of the invention of the internet and concomitant technologies on the change of communication and interaction patterns, both on the macro level as well as on the micro level. These technologies are, in turn, based on prior scientific innovations that, at the time of their invention, appeared to have no pragmatic use at all, for example the binary algebra George Boole had elaborated.

Within the complexity of Parsons' general theory of action, we can conclude that any part of the general action system may induce social change. Social conflict is neither a sufficient nor a necessary condition for social change.

\section{Conclusion}

In one of his first publications, Talcott Parsons wrote that distortions in the characterization of society are rooted "in the isolation of one aspect of social development" (1991 [1928]: 35). Some fifty years later, in looking back to his achievements and the challenges he had to face, he summarized: "A large part of the hierarchy - power preoccupation of so much generalized social thought of the last century or so I attribute to ideological factors." (1977 [1970]: 57). In between, he dedicated his life to overcoming ideological one-sidedness and reductionism of all sorts in human sciences, which he accomplished by theoretical syntheses and conceptual differentiations. The result is a highly complex multi-dimensional "frame of reference" for achieving empirical knowledge of society.

In his review of Mills' The Power Elite, Parsons started his argument on the shortcomings of Mills' analysis by stressing the importance of such differentiated "technical theoretical schemes" (1956: 124) in order to prevent "ideological distortion" (125) in the interpretation of empirical data. Mills' interpretation of Parsons as a grand theorist is an ideological distortion, in this sense grounded in a deficient theoretical scheme he charmingly had called the sociological imagination.

The "prophet who came in from a desert" found many followers. His polemical writing style resonated well with the emerging political culture with its predilection for "style over substance, outrage over objectivity..." (Goertzel 1989: 244-5). His theoretical core displays a close affinity to the theories of the stylites of contemporary sociology, such as Pierre Bourdieu or Michelle Foucault. Seymour Martin Lipset, in his essay on the state of American sociology, elaborated on the thesis "that the parlous state of sociology ... (is) related to its vulnerability to politicization" (1994: 199). What he obviously referred to was not the political use of sociological knowledge but the usurpation of the sociological imagination by political interests. Perhaps political agendas do require simplifications, such as the isolation of specific goals for their 
effective pursuit. However, imposing the simplifications and concomitant restraints on scholarly reasoning leads to its collapse. For the tree of knowledge does not resemble an upright sailing mast, but rather a widely ramified plant that requires abundant free space for further growth. It will be one of the most important criteria for any future sociological imagination to procure such a prospect.

Acknowledgements I want to thank Victor M. Lidz, Lawrence T. Nichols, A. Javier Treviño, Bruce C. Wearne, and two anonymous reviewers for their critique and helpful comments on a prior version of this essay.

Funding Open access funding provided by University of Innsbruck and Medical University of Innsbruck.

\section{Compliance with Ethical Standards}

Conflict of Interest There is no conflict of interest associated with this paper.

Open Access This article is licensed under a Creative Commons Attribution 4.0 International License, which permits use, sharing, adaptation, distribution and reproduction in any medium or format, as long as you give appropriate credit to the original author(s) and the source, provide a link to the Creative Commons licence, and indicate if changes were made. The images or other third party material in this article are included in the article's Creative Commons licence, unless indicated otherwise in a credit line to the material. If material is not included in the article's Creative Commons licence and your intended use is not permitted by statutory regulation or exceeds the permitted use, you will need to obtain permission directly from the copyright holder. To view a copy of this licence, visit http://creativecommons.org/licenses/by/4.0/.

\section{References}

Bershady, H. J. (2014). Ideology and social knowledge. New Brunswick: Transaction Publishers.

Bershady, H. J. (2016). When Marx mattered: An intellectual odyssey. New Brunswick: Transaction Publishers.

Durkheim, E. (1982 [1895]). The rules of sociological method. London: Palgrave.

Garfinkel, H. (2019). Parsons’ Primer. In A. W. Rawls (Ed.), Parsons primer. Berlin: J. B. Metzler.

Gerth, H., \& Mills, C. W. (1953). Character and social structure. The psychology of social institutions. New York: Harcourt Brace Jovanovich Publishers.

Goertzel, T. G. (1989). "The causes of world war III": Thirty years later. Sociological Forum, 4(2), 241-246. Lidz, V. (2019). Strengthening the strong program in cultural sociology. Innsbruck: Innsbruck University Press.

Lidz, V., Staubmann, H. 2020. Power in the context of homeostasis of the polity. Paper for presentation at the 2020 ASA meeting.

Lipset, S. M. (1994). The state of American sociology. Sociological Forum, 9(2), 199-220.

Mahlert, B. (2020). Addressing Parsons in sociological textbooks: Past conflicts, contemporary readers, and their future gains. The American Sociologist, 51(4).

Mills, C. W. (1956). The power elite. New York: Oxford University Press.

Mills, C. W. (1958). The causes of world war III. New York: Ballantine books. New York: Oxford University Press.

Mills, C. W. (1959). The sociological imagination. New York: Oxford University Press.

Mills, K. 2018. C. Wright Mills through his letters - His time in Innsbruck and the making of The Sociological Imagination. Austrian Journal of Political Science, 47 (4). https://doi.org/10.15203/ozp.2847.vol47iss4.

Mills, K. with Mills, P. (ed.) (2000). C. Wright Mills. Letters and autobiographical writings. Berkeley: University of California Press.

Parsons, T. (1937). The structure of social action. New York: The Free Press. 
Parsons, T. (1954 [1949]). Essays in sociological theory. New York: Free Press.

Parsons, T. (1951). The social system. The major exposition of the Author's conceptual scheme for the analysis of the dynamics of the social system. New York: Free Press.

Parsons, T. (1957). The distribution of power in American society. Review of The Power Elite by C. Wright Mills. World Politics, 10(1), 123-143.

Parsons, T. (1969). On the concept of political power. In T. Parsons (Ed.), Politics and social structure (pp. 352-404). New York: Free Press.

Parsons, T. (1977). On building social systems theory: A personal history. In T. Parsons (Ed.), Social systems and the evolution of action theory (pp. 22-76). New York: Free Press.

Parsons, T. (1991 [1928]). "Capitalism” in recent German literature: Sombart and Weber. In C. Camic (Ed.), Talcott Parsons: The early essays (pp. 3-37). Chicago: University of Chicago Press.

Parsons, T., \& Platt, G. (1973). The American University. New York: Free Press.

Rawls, A. W., Turowetz, J. (2019.) "Discovering culture "in interaction: Solving problems in cultural sociology by recovering the interactional side of Parsons' conception of culture. American Journal of Cultural Sociology. https://doi.org/10.1057/s41290-019-00079-6.

Simmel, G. 2000 [1908]). Soziologie. Untersuchungen über die Formen der Vergesellschaftung. Frankfurt: Suhrkamp.

Staubmann, H. (2005). Culture as a subsystem of action: autonomous and heteronomous functions. In R. Fox, H. J. Bershady and V. M. Lidz Eds.), After Parsons: A Theory of Social Action for the 21st Century. New York: Russell Sage. pp. 169-78.

Staubmann, H., Treviño, A. J. (2018). Introduction to: Kathryn Mills: C. Wright Mills through his letters - His time in Innsbruck and the making of The Sociological Imagination. Austrian Journal of Political Science, 47(4). https://doi.org/10.15203/ozp.2846.vol47iss4.

Treviño, A. (2017). C. Wright Mills and the Cuban Revolution. An Exercise in the Art of Sociological Imagination. Chapel Hill: The University of North Carolina Press.

Turowetz, J., Rawls, A. (forthcoming). Talcott Parsons and Harold Garfinkel: The development of culture in interaction. In J. Treviño and H. Staubmann (Eds.), The Routledge International Handbook of Talcott Parsons Studies. London: Routledge.

Weber, M. (2019 [1922]). Economy and society. A new translation. Edited and translated by K. Tribe. Cambridge, Mass. Harvard University press.

Wrong, D. H. (1961). The Oversocialized conception of man in modern sociology. American Sociological Review, 26(2), 183-193.

Publisher's Note Springer Nature remains neutral with regard to jurisdictional claims in published maps and institutional affiliations. 